09

\title{
Стабилизация спектра генерации твердотельного импульсного Nd-YAG-лазера с многопетлевым резонатором
}

\author{
(C) А.П. Погода ${ }^{1}$, А.А. Сергеев ${ }^{1}$, А.В. Федин ${ }^{1}$, А.С. Иванов ${ }^{2}$, \\ Н.В. Никоноров ${ }^{2}$
}

${ }^{1}$ Балтийский государственный технический университет „BОЕНMЕХ“ им. Д.Ф. Устинова, Санкт-Петербург

${ }^{2}$ Санкт-Петербургский национальный исследовательский университет информационных технологий, механики и оптики

E-mail: Pogoda@lsystems.ru

Поступило в Редакцию 17 ноября 2016 г.

Предложен способ стабилизации частоты и сужения ширины полосы генерации импульсного твердотельного Nd-YAG-лазера с динамическим самоадаптивным многопетлевым резонатором путем введения внутрирезонаторной стационарной объемной брэгговской решетки. Это позволяет зафиксировать частоту и уменьшить ширину спектральной линии генерации с 18 до 4 pm.

DOI: 10.21883/PJTF.2017.08.44539.16571

Применение методов самообращения волнового фронта (самоОВФ) позволяет создавать компактные лазерные системы с большой энергией, пиковой мощностью и высоким оптическим качеством импульса модулированного излучения, обладающие к тому же малыми массогабаритными характеристиками [1-3]. Мощное излучение с высокой пространственной яркостью требуется для решения многих практических задач обработки материалов, спектроскопии, преобразования в актуальные спектральные диапазоны, голографии [4-7].

Подобные лазерные системы с самоОВФ были реализованы как с ламповой [4], так и с диодной [3] накачкой. Исследования, проведенные нами на наиболее широко применяемых активных средах, таких как алюмоиттриевый гранат с неодимом (Nd:YAG), гадолиний-галлиевый гранат с неодимом (Nd:GGG), силикатные и фосфатные стекла с неодимом, показали [1-10], что самоОВФ в результате дифракции на 
динамических решетках коэффициента усиления, записанных непосредственно в активной среде, позволяет получать одномодовое, близкое к одночастотному, излучение цугов наносекундных импульсов, энергия которых может достигать $0.5 \mathrm{~J}$ при пиковой мощности до $20 \mathrm{MW}$ и пространственной яркости до $5 \cdot 10^{14} \mathrm{~W} /\left(\mathrm{cm}^{2} \cdot \mathrm{sr}\right)$. При этом в отдельных случаях удается получать одночастотные импульсы генерации с шириной полосы около $1 \mathrm{pm}(\sim 300 \mathrm{MHz})$. Это обусловлено спектральной селекцией при более высокой эффективности обратной связи для основной моды, которая преодолевает порог генерации значительно раныше и имеет более высокое превышение над порогом, чем остальные моды.

Однако при больших превышениях над порогом частота генерации произвольным образом изменяется от импульса к импульсу в пределах центральной части полосы усиления активной среды. Такая нестабильность существенно ограничивает применение данного лазера [7-10].

Перспективным путем решения данной задачи представляется применение комплексного стационарно-динамического голографического способа, в котором для формирования динамических решеток коэффициента усиления вводится дополнительный селектирующий элемент стационарная объемная брэгговская решетка, применение которой во внешнем резонаторе полупроводникового лазера [11] позволяло эффективно стабилизировать длину волны и сужать ширину полосы генерации.

Задачей представленной работы является исследование влияния внутрирезонаторной пропускающей объемной брэгговской решетки на спектральную ширину излучения $\mathrm{Nd}$ : YAG-лазера с динамическим самоадаптивным многопетлевым резонатором.

В настоящей работе использована малогабаритная лазерная система с самоОВФ при многоволновом взаимодействии в активной (усиливающей) среде и среде пассивного лазерного затвора (ПЛЗ).

Для исследования лазерной генерации использован квантрон с цилиндрическим активным элементом $\mathrm{Nd}$ :YAG $\left(1.1 \mathrm{at} . \% \mathrm{Nd}^{3+}\right)$ размером $6.3 \times 100 \mathrm{~mm}$. Поперечная четырехсторонняя импульсно-периодическая накачка активного элемента (АЭ) осуществлялась двенадцатью матрицами лазерных диодов типа СЛМ 3-2 с размерами излучающей площадки $5 \times 25 \mathrm{~mm}$ и пиковой мощностью до $2 \mathrm{~kW}$ каждая. Максимальная энергия накачки составила $10.3 \mathrm{~J}$. В качестве ПЛ3 применяли кристалл $\mathrm{LiF}: \mathrm{F}_{2}^{-}$с начальным пропусканием $T_{0}=14 \%$ и длиной $51.5 \mathrm{~mm}$. Длина лазера составляла $55 \mathrm{~cm}$.

Письма в ЖТФ, 2017, том 43, вып. 8 


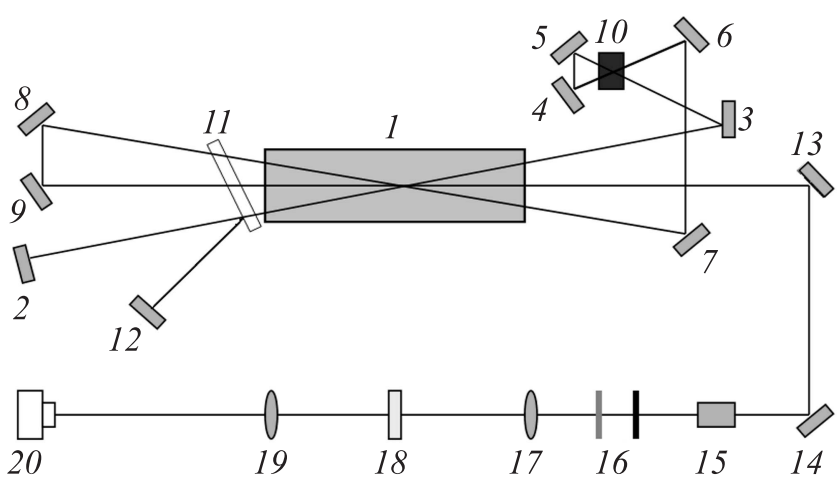

Рис. 1. Оптическая схема проведения эксперимента: 1 - активный элемент; 2,12 - глухие зеркала; 3-9, 13, 14 - поворотные зеркала; 10 - пассивный затвор LiF: $\mathrm{F}_{2}^{-}$(начальное пропускание $T_{0}=14 \%$ ); $11-$ стационарная брэгговская решетка; 15 - нелинейный кристалл для получения второй гармоники; 16 - инфракрасный и нейтральный фильтры; 17, 19 - линзы; 18 - эталон Фабри-Перо; 20 - ПЗС-матрица.

Оптическая схема лазера представлена на рис. 1. Лазер состоит из одного АЭ 1 , глухого зеркала 2, шести поворотных зеркал 3-9 и ПЛЗ 10. Для стабилизации частоты и сужения спектра генерации была использована пропускающая объемная брэгговская решетка 11 , записанная в фототерморефрактивном стекле [12], синтезированном в университете ИТМО. За счет чисто фазового характера записываемых решеток данный материал предоставляет возможность получения решеток с дифракционной эффективностью до 99\%. Решетка была записана с помощью УФ-излучения $\mathrm{He}-\mathrm{Cd}$-лазера $(325 \mathrm{~nm})$ под длину волны генерации в $1064 \mathrm{~nm}$ в объеме стекла толщиной $1 \mathrm{~mm}$. Угол дифракции на рабочей длине волны был выбран $27.1^{\circ}$. Дифракционная эффективность записанной решетки составила $75 \%$.

Исследования проводили путем сравнения спектрального состава излучения лазера с брэгговской решеткой и без нее. Решетку 11 (рис. 1) устанавливали по ходу распространения лучей в резонаторе перед глухим зеркалом 2 таким образом, чтобы условие Брэгга выполнялось только для излучения, распространяющегося в направлении зеркала 2. Для остальных внутрирезонаторных пучков условие Брэгга не выполняется, поэтому они с решеткой не взаимодействовали благодаря высокой 


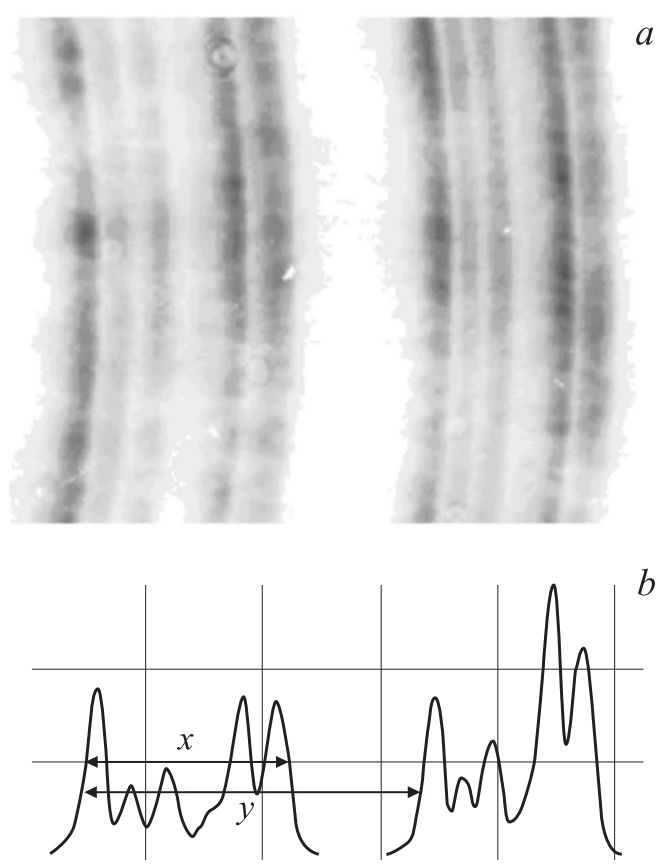

Рис. 2. Сравнение спектра лазера в режиме генерации цуга импульсов: интерферограмма $(a)$ и ее сечение $(b)$ в отсутствие стационарной брэгговской решетки; интерферограмма $(c)$ и ее сечение $(d)$ при наличии в схеме стационарной брэгговской решетки.

угловой селективности используемой решетки. Так как дифракционная эффективность решетки превышала $90 \%$, то зеркало 2 в формировании генерации не участвовало. Вместо этого в первом порядке дифракции на эквивалентном расстоянии устанавливали зеркало 12 для обеспечения обратной связи.

Измерения спектрального состава излучения проводили путем преобразования его во вторую гармонику с помощью нелинейного кристалла 15 (рис. 1). Излучение второй гармоники, прошедшее через инфракрасный и нейтральный фильтры 16 , а также расширяющую пучок линзу 17, попадают на эталон Фабри-Перо 17 с интервалом свободной дисперсии $28 \mathrm{pm}$. Далее полученная интерферограмма проецируется

Письма в ЖТФ, 2017, том 43, вып. 8 


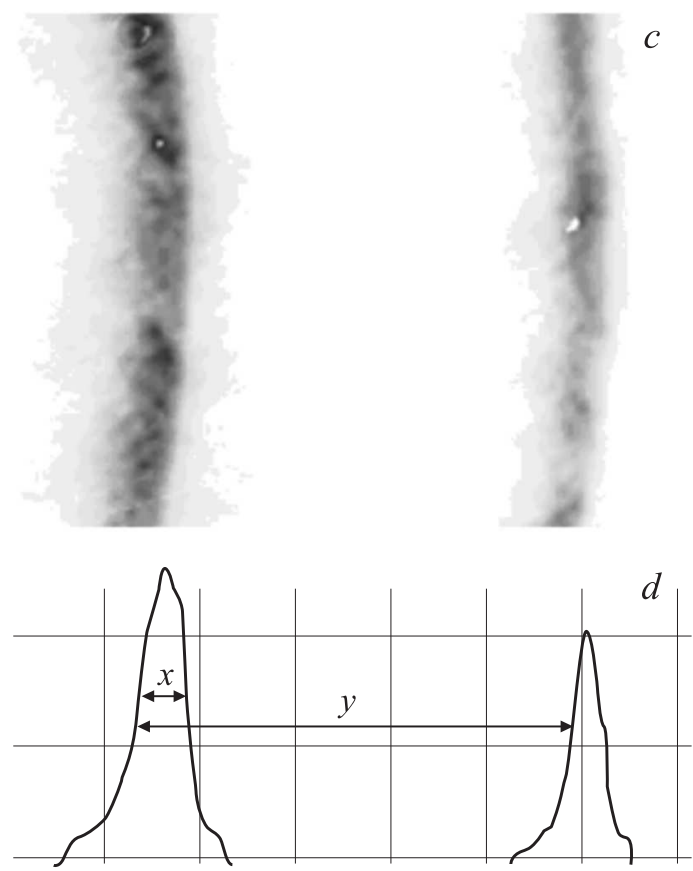

Рис. 2 (продолжение).

линзой 19 на ПЗС-матрицу камеры Ophir-Spiricon 20. Полученную интерферограмму обрабатывали с помощью программного пакета Fiji, позволяющего построить сечение интерферограммы.

Лазерная система работает следующим образом. Генерация начинается с шумового излучения в АЭ. По мере развития генерации внутрирезонаторными пересекающимися пучками в АЭ записываются пропускающие решетки коэффициента усиления и решетки показателя преломления в ПЛЗ, образующие самоподстраивающийся адаптивный резонатор лазера. На образовавшихся решетках происходят перераспределение поля излучения и обращение его волнового фронта. При установке стационарной объемной брэгговской решетки она выделяет центральные компоненты контура усиления уже на стадии шумового излучения, что приводит к стабилизации частоты генерации лазера.

Письма в ЖТФ, 2017, том 43, вып. 8 
Записанные в активной среде динамические решетки совместно со стационарной брэгговской решеткой производят селекцию пространственных, спектральных и поляризационных компонентов излучения. ПЛ3 реализует режим пассивной модуляции добротности и позволяет получить излучение в виде цуга импульсов наносекундной длительности.

На рис. 2 представлены интерферограммы и их сечения, полученные в режиме генерации цуга из 11 импульсов, без брэгговской решетки $(a, b)$ и после ее установки $(c, d)$. Видно, что в первом случае интерферограмма содержит 2-6 колец в рамках одного порядка интерференции, что свидетельствует о наличии соответствующего количества продольных мод. Суммарная ширина полосы определялась по формуле $x / y \cdot \Delta \lambda$, где $x$ - расстояние между крайними модами на интерферограмме, $y$ - расстояние между соседними порядками на интерферограмме, $\Delta \lambda$ - интервал свободной дисперсии, равный $28 \mathrm{pm}$. Полученные результаты показали, что без решетки суммарная спектральная ширина составила $18 \mathrm{pm}$, а при использовании решетки - не превышала 4 pm. При этом центральная частота излучения оставалась постоянной.

Таким образом, применение комплексного стационарно-динамического голографического способа позволило стабилизировать частоту и сузить с 18 до 4 pm ширину полосы генерации твердотельного импульсного самоОВФ-лазера с поперечной диодной накачкой. При этом излучение лазера обладает высокой энергией в импульсе до $100 \mathrm{~mJ}$, пиковой мощностью до $10 \mathrm{MW}$ и спектральной яркостью до $6 \cdot 10^{13} \mathrm{~W} /\left(\mathrm{cm}^{2} \cdot \mathrm{sr} \cdot \mathrm{pm}\right)$, что делает лазер полезным для решения широкого круга практических задач.

Исследование выполнено за счет гранта Российского научного фонда (проект № 14-23-00136).

\section{Список литературы}

[1] Лебедев В.Ф., Погода А.П., Сметанин С.Н. и др. // ЖТФ. 2014. Т. 84. В. 12. C. $107-111$.

[2] Pogoda A.P., Lebedev V.F., Makarchuk P.S. et al. // Optical Memory and Neural Networks. 2013. V. 22. N 4. P. 267-271.

[3] Погода А.П., Бурковский Г.В., Макарчук П.С. и др. // Письма в ЖТФ. 2016. T. 42. B. 6. C. $35-41$.

Письма в ЖТФ, 2017, том 43, вып. 8 
[4] Басиев Т.Т., Федин А.В., Гаврилов А.В. // Квантовая электроника. 1999. Т. 27. № 2. C. $145-148$.

[5] Басиев Т.Т., Карасик А.Я., Осико В.В. и др. // Квантовая электроника. 2009. T. 39. № 4. C. 385-387.

[6] Басиев Т.T., Басиева М.Н., Гаврилов А.В. и др. // Квантовая электроника. 2010. T. 40. № 8. С. 710-715.

[7] Солохин С.А., Сметанин С.Н., Гаврилов А.В. и др. // Известия РАН. Сер. Физ. 2012. Т. 76. № 10. С. 1242-1246.

[8] Basiev T.T., Fedin A.V., Osiko V.V. et al. // Laser Phys. 2001. V. 11. N 6. P. $807-$ 809.

[9] Басиев Т.T., Сметанин С.Н., Федин А.В. и др. // Оптика и спектроскопия. 2009. T. 107. B. 3. C. 378-384.

[10] Федин А.В., Сметанин С.Н., Шепелев А.Е. и др. // Оборонная техника. 2013. № 7-8. C. $80-82$.

[11] Ivanov S.A., Nikonorov N.V., Ignat'ev A.I. et al. // Semiconductors. 2016. V. 50. N 6. P. 819-823.

[12] Ivanov S.A., Ignatiev A.I., Nikonorov N.V. et al. // J. Opt. Technol. 2014. V. 81. N 6. P. $356-360$. 